\title{
NATUREZA E CULTURA NA FOTOGRAFIA DE TIAGO SANTANA
}

\section{NATURE AND CULTURE IN TIAGO SANTANA'S PHOTOGRAPHY}

TÉRCIA Montenegro LEMOS *

RESUMO: Nosso artigo, resultado de uma recente pesquisa em semiótica visual, pretende investigar a construção do sentido em imagens de autoria do fotógrafo cearense Tiago Santana. A semiótica, como teoria da relação, une termos - que podem ser unidades significantes de qualquer grandeza - do ponto de vista da significação. Assim, os componentes visuais de uma foto podem ser entendidos como termos constituintes de um sentido, na medida em que se põem numa dimensão relacional. Tais relações se articulam em diferentes níveis de análise, conforme sabemos pelo modelo da semiótica greimasiana, que indica procedimentos que vão desde a construção de um programa narrativo num percurso global (capaz de simular a geração de sentido da estrutura profunda à estrutura de superfície) até abrir espaço, mais recentemente, para as aplicações da semiótica tensiva, utilizada em nossa análise. Com fundamentação teórica também respaldada pelos estudos de Floch (1985), Pietroforte (2007) e Dondero (2008 e 2011), obtivemos resultados esclarecedores em torno da opo-

* Docente da UFC - Universidade Federal do Ceará. E-mail: literatercia3@gmail.com. 
sição fundamental humano/cultura vs. animal/natureza, observada na construção de um universo sertanejo em cinco fotografias de nosso corpus de base.

PALAVRAS-CHAVE: Semiótica. Fotografia. Tiago Santana.

ABSTRACT: Our article results of a recent research in visual semiotics and intends to investigate the process of sense in images from the photographer Tiago Santana from Ceará. Semiotics, as a relationship theory, puts elements together that can be significant units of any magnitude, from the point of view of meaning. So, the visual components of a picture can be understood as terms of a sense being in a relationship dimension. These relationships work in different levels of analysis as we know from the model of the Greimasian semiotics, revealing a process which involves from the construction of a narrative programming in a global trajectory (able to simulate the generation of meaning from the deep structure to the superficial one) until the opening, recently, of a field to the tensive semiotics used in our analysis. Using as theoretical framework also the studies by Floch (1985), Pietroforte (2007) and Dondero (2008, 2011), we have found clarifying results of the opposition human/culture $v s$. animal/nature, observed in the construction of a country field in five photographs from our base corpus.

KEYWORDS: Semiotics. Photography. Tiago Santana. 


\section{Introdução}

Nossa pesquisa busca analisar a obra do fotógrafo Tiago Santana à luz da teoria semiótica. Natural da região do Cariri, no Nordeste brasileiro, Santana é considerado um autor de expressão internacional, especialmente após integrar a prestigiosa coleção francesa Photo Poche, de livros de fotografia. Além desta publicação, intitulada Sertão (2011), Santana editou pela Tempo D'Imagem as obras Benditos (2000), O chão de Graciliano (2006) e Céu de Luiz (2014), dentre outras.

Dando privilégio a paisagens sertanejas, suas fotografias discutem a relação ser humano/animal, e a maioria das imagens com essa temática privilegia o animal em primeiro plano, com o homem reduzido ao fundo, ou então representado de forma anônima (com o rosto cortado, ou na sombra, ou envolto por algum tecido etc.). É o que, em estudo introdutório, Eduardo Manet chamou de "ideia barroca da profunda fecundidade do caos"1.

Se por um lado os cortes e ângulos agressivos da fotografia de Tiago Santana parecem justificar o "caos" que se revela fecundo pelas diversas possibilidades de leitura, por outro lado a "ideia barroca" também está mantida, sobretudo se considerarmos a caracterização desta estética conforme a clássica obra de Wölfflin (2006), a partir da qual o barroco, por explorar o estilo pictórico (em oposição ao estilo linear), trabalha com uma "emancipação das massas de claro e escuro que, num jogo autônomo, buscam-se umas às outras" (WÖLFFLIN, 2006, p. 27). Veremos justamente essa complementaridade de formas, ao mesmo tempo em que observamos sua autonomia, na análise das fotografias de nosso corpus.

1 No original, "l'idée baroque de la profonde fécondité du chaos". In Sertão - photographies de Tiago Santana. Tours: Actes Sud, 2011. 
Um primeiro contato com as imagens que constituem nosso corpus já levanta a construção do "parecer ser" sertanejo, em termos semióticos. As escolhas representativas de Tiago Santana costumeiramente dispõem a figura humana em relação presencial com os bichos, e estes inclusive surgem em realce ou com maior nitidez, em detrimento da pessoa, que costuma aparecer com o rosto encoberto ou desfocado, ou ainda com menor peso visual devido a tratamentos de luz, contraste ou textura, dentro da foto.

Partindo da oposição fundamental humano/cultura vs. animal/natureza, veremos como o texto fotográfico se articula e como a semiótica tensiva pode ser usada para problematizar a dimensão contínua de seu sentido. Obviamente, levamos em conta que a imagem fotográfica tem uma linguagem própria e, em decorrência disso, possui seus próprios arranjos sintáticos; por outro lado, embora parta de uma captação do real a partir de elementos efetivamente físicos, a fotografia não deve ser tomada como um mero recorte ou extrato da realidade. A sua realização, embora quase sempre seja dependente (e, portanto, conflitante) em relação ao mundo natural ${ }^{2}$, não se confunde com ele. Fotografia não é mundo, não é referente puro; é, assim como toda e qualquer linguagem, uma tradução do mundo e uma maneira de impossibilitar o contato direto com ele, no momento em que introduz a intermediação de um signo. Apenas ocorre que a fotografia, enquanto obra que resulta da síntese de signos visuais, talvez enfatize mais a "impressão referencial" (BERTRAND, 2003, p. 233) e, portanto, a figuratividade, mais do que outras linguagens.

2 Fazem-se exceção para as fotografias que se valem de procedimentos exclusivamente computadorizados em seu processo criativo. Entretanto, como estas fogem ao nosso propósito analítico, não levaremos em conta suas particularidades. 
A dimensão figurativa, de exploração do sensível, numa fotografia, envolve um tipo de análise que não somente passa pelos elementos que constituem a expressão da linguagem visual, a saber, os seus cinco pilares essenciais: linha, superfície, luz, volume e cor. Considerações acerca da composição visual, a partir da regra dos terços, do uso de texturas, enquadramentos específicos, sombras, reflexos etc. devem ser levados em consideração para o resultado estético intencional. Entretanto, começamos a especificar nossa abordagem ao observar que a dimensão visual é passível de ser analisada semioticamente através de seus formantes, no caso da fotografia apresentados em subordinação às categorias eidética, topológica, cromática e material, que os compõem. Mais do que isso, temos de constatar, com Dondero (2008), que o "corpo enunciante" de uma fotografia é um aspecto essencial da análise, exigência da característica autográfica ${ }^{3}$ deste tipo de arte.

Após investigações conduzidas em pesquisa com o corpus mínimo de cinco fotografias, elencamos algumas estratégias de linguagem que nos esclarecem sobre a maneira pela qual ocorre a discursivização das estruturas nas fotografias classificadas dentro da oposição fundamental que foi objeto de nossa seleção. Observaremos como a categoria formal humano/cultura vs. animal/natureza ilustra uma tensão estabelecida conforme as propostas de Fontanille e Zilberberg (2001) e, assim, teremos dois eixos contínuos, o da intensidade e o da extensidade, a levar em conta em nossa descrição. Nossa hipótese inicial sugere que o eixo da extensidade pode ser definido pelo elemento humano. Para justificar, lembra-

3 Embora a semiótica greimasiana não distinga entre autografia ou alografia, para a análise de um texto visual é indispensável pensar na relação entre o suporte das formas e a modalidade de sua inscrição. 
mos que os domínios da globalidade, ou do extenso, parecem realmente corresponder, na fotografia, à medida do que é humano, não somente pelo fato de que a foto é um produto artístico que depende do olhar (e do enquadramento, do gesto etc.) de uma pessoa, mas também porque sua existência só foi possível, historicamente, pela invenção de um instrumento, a câmera: um produto cultural, construído pelo homem.

Entretanto, uma modalização se faz necessária em nosso esboço tensivo, visto que a intensidade aponta para os investimentos de valor e para o engajamento do sujeito (traços que recaem sobre o elemento humano), assim como a extensidade diz respeito ao desdobramento espaço-temporal das figuras (o que, numa fotografia, atinge a sua realização por inteiro). Com tal ressalva, nossa hipótese se sustenta a partir da afirmação de Zilberberg (2011, p. 70, grifo nosso), de que "a intensidade, como dimensão, rege a extensidade". Nada mais evidente em nosso corpus, cuja prevalência da presença do animal ocorre em detrimento da figura humana. Dessa maneira, em nosso estudo, embora dispensemos as clássicas representações em formato de gráfico tensivo de Fontanille e Zilberberg (2001), não nos furtamos à análise da diretividade da foria tensão/relaxamento, através de reflexões que evidenciam os elementos relacionados à natureza e cultura, nos exemplos adotados. 


\section{Análise das fotografias}

\subsection{Primeira foto}

Figura 1 - Santana do Ipanema, 2005

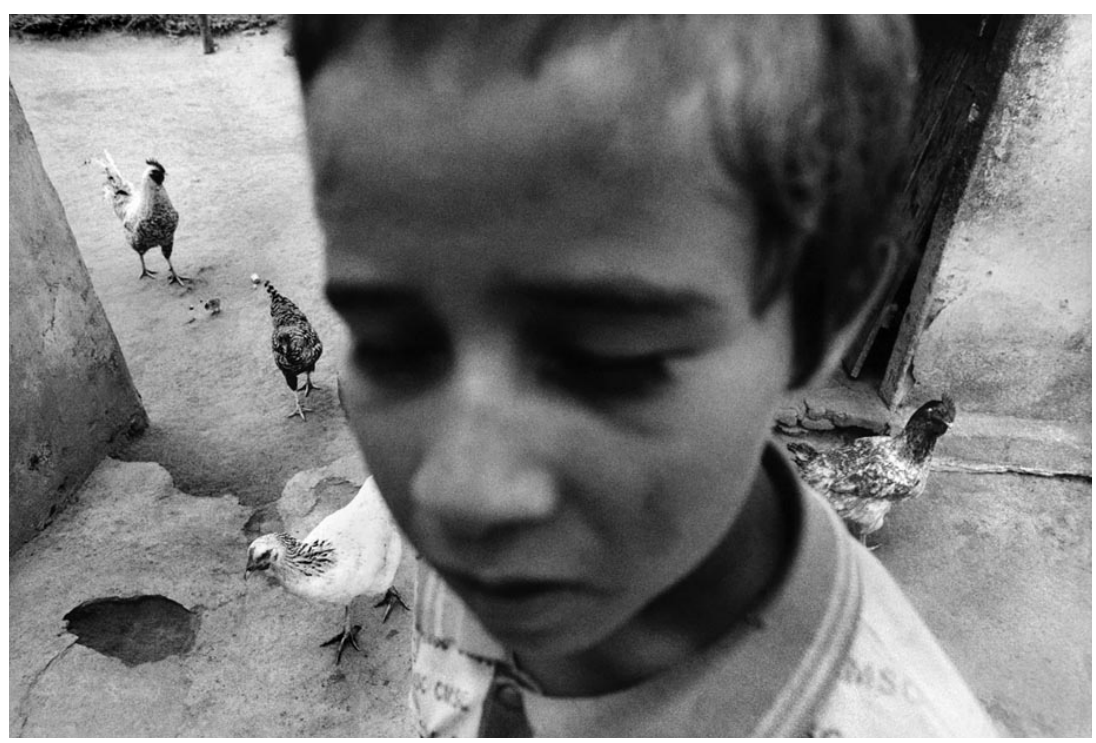

Fonte: Santana (2011)

Logo numa primeira visada, a foto demonstra que o menino se aparta dos animais, seja pela grande proximidade com a câmera, seja pela altura. A oposição fundamental se apresenta, no nível narrativo, através de um mecanismo de disjunção evidenciado pela diferença de ocupação espacial entre o sujeito (ser humano) e os demais seres (os animais, aqui ocupando a posição do outro, ou seja, do objeto). Assim, percebemos o rosto do menino bem próximo de nós e alto, enquanto os animais aparecem distantes, numa escala reduzida (devido à própria perspectiva) e ocupando os planos médio ou baixo, preferencialmente. 
Entretanto, embora o rosto do menino ocupe a maior parte da dimensão visual, e ainda esteja numa posição centralizada e elevada, a pouca nitidez dada a seus traços fisionômicos leva o olhar do espectador às figuras que estão verdadeiramente em foco - no caso, as galinhas. Estas têm a sua importância adensada pelo dinamismo das diferentes posturas que assumem, com seus corpos escuros ou pintalgados destacando-se contra um fundo mais claro. $\mathrm{O}$ aspecto geométrico de sua distribuição na cena assume uma disposição em triângulo invertido, construída a partir do rosto e dos ombros do menino. É valioso observar como tal modelo de composição remonta a exemplos clássicos; podemos, nesse sentido, comparar a fotografia em questão com a Virgem anunciada, de Antonello da Messina, obra que, segundo Roberto Longhi (2005, p. 10), é um perfeito caso de estilo perspectivo de forma:

[...] imaginando que a pirâmide visual que tem por base a tela e por foco o centro do horizonte está, além disso, dividida em muitos planos ideais que, mesmo não representados, estão simbolizados no efeito produzido sobre a forma, que assim resulta nivelada e disposta, no conjunto, ao longo de certos planos, tal como ocorre com uma massa arquitetônica.

Voltando à fotografia de nossa análise, ainda observamos que o rosto da criança parece assumir, em sua disposição, e conforme o ângulo adotado - plongé - a forma de dois triângulos unidos pelo vértice, tal como poderíamos notar melhor com as linhas ressaltadas sobre a imagem: 
Figura 2 - Análise de Santana do Ipanema, 2005

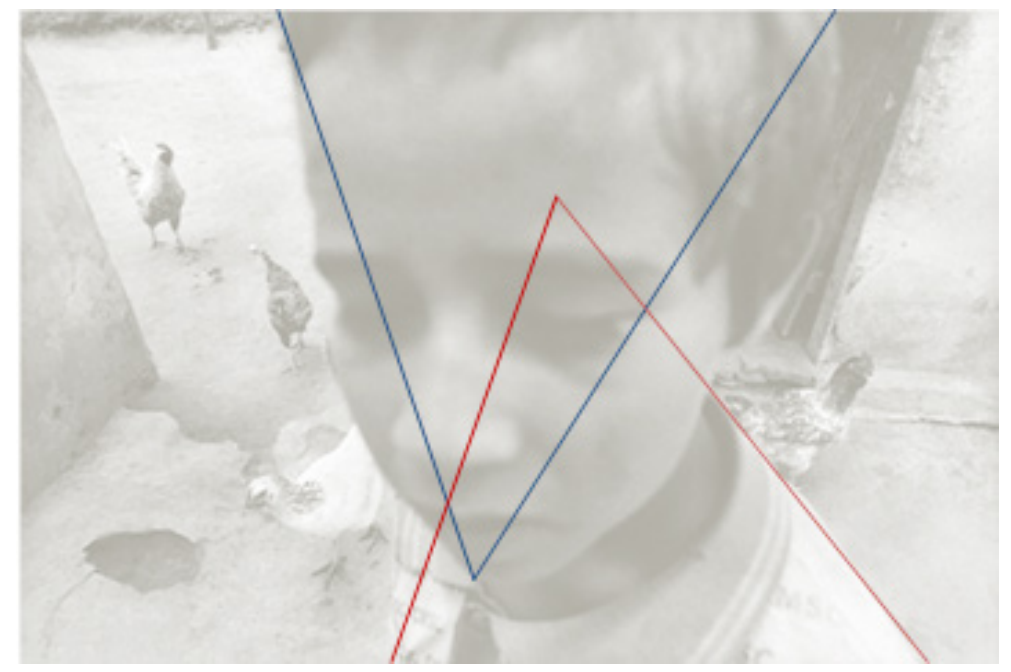

Fonte: Santana (2011)

Ora, o encontro destas duas formas triangulares sugere o formato de uma ampulheta, representação do tempo que, não à toa, está associada à figura humana. Reflexões sobre o passado, a efemeridade da vida e a implacabilidade da morte acompanham o ser humano desde sempre - e nesta fotografia o valor do tempo tem seu tema adensado pela presença da criança, que por sua própria condição etária indica um limiar cronológico aberto a várias expectativas.

Esta criança, porém, tem o rosto deformado pelo ângulo escolhido e pela proximidade com a câmera, que lhe rouba a nitidez dos traços. A deformidade que o desfoque confere à fisionomia humana leva a uma desvalorização de sua presença na imagem. 0 menino se torna mais anônimo do que os bichos - e as implicações que este laivo interpretativo lança são cruciais para entender o par natureza/cultura na construção da paisagem sertaneja. Eis o que já podemos depreender de nos- 
sas reflexões até este ponto:

A oposição fundamental natureza vs. cultura expressou-se, na primeira fotografia do corpus, através do movimento de disjunção entre homem e animal. Este último é favorecido, conforme se percebe pela sintaxe discursiva da linguagem fotográfica. Entretanto, aplicando os princípios da semiótica tensiva, não poderemos deixar de atribuir uma maior carga de intensidade à figura humana (pela sua deformidade, pela proximidade extrema, pela grande ocupação espacial), ao passo que as galinhas representam confortavelmente o ponto da extensividade (por sua presença repetitiva, indicando a manutenção no campo de presença, e também por sua nitidez imagética, pela ocupação harmoniosa das margens da fotografia). Este raciocínio à primeira vista parece confortável, pela legítima associação do sensível ao humano: este por si já supõe "estados de alma", enquanto que os animais, aqui assimilados aos objetos, apontam sem problema para "estados de coisas". Não nos precipitemos em tirar conclusões, porém; passemos à análise das outras fotografias, para termos um entendimento mais amplo. 


\subsection{Segunda foto}

Figura 3 - Água Branca, 2005

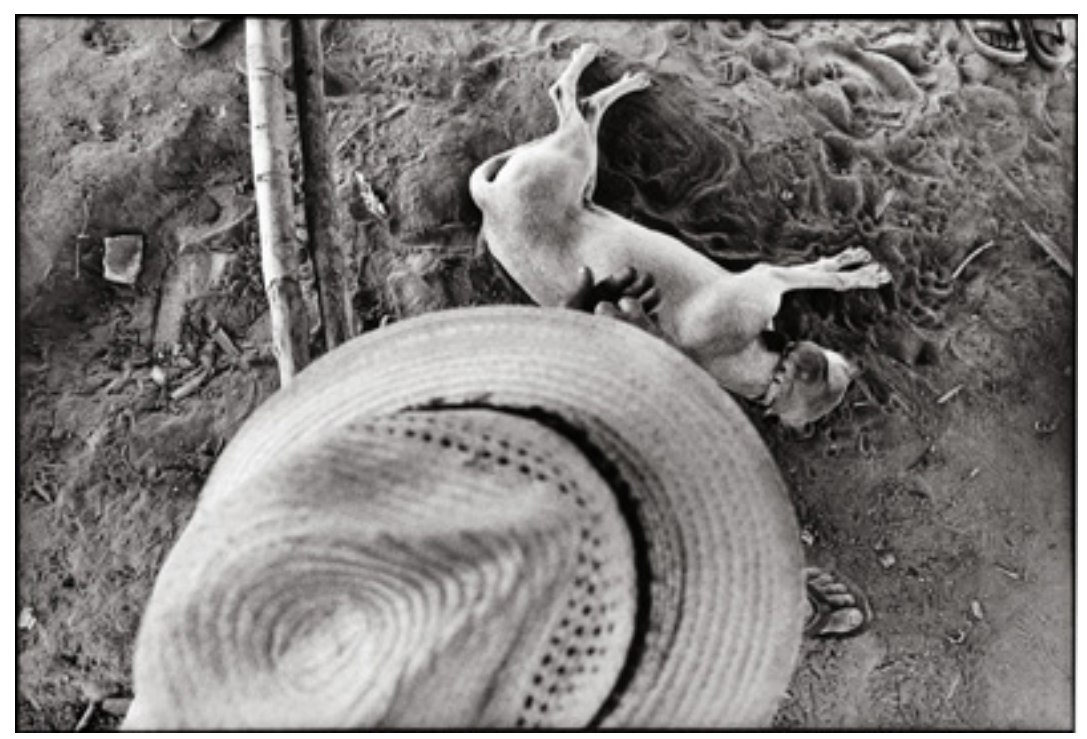

Fonte: Santana (2011)

Aqui, novamente percebemos a oposição fundamental que motiva nossa investigação sobre as fotografias de Tiago Santana. A cultura está representada pelo chapéu, sob o qual se supõe a presença humana, confirmada pela presença das mãos e de um pé calçado. É importante constatar como tais extremidades prolongam a forma de triângulo já esboçada pela copa, amassada, do chapéu. Ao mesmo tempo, as circularidades são muito visíveis na foto: pelo chapéu também, que reprisa os círculos no traçado da palha e na fita preta; pelo arredondado do pé; pelas mãos que se unem e pelas modulações dos músculos nas pernas do cachorro e em sua cauda. 0 animal repousa sobre um terreno arenoso, em que as sinuosidades são igualmente visíveis, através de sulcos e ondulações. 
Se acompanharmos este relevo nos extremos superiores da fotografia, temos a surpresa de encontrar mais pistas humanas: no lado esquerdo, dois pés calçados e, quase no extremo direito, um chinelo, vazio, mas que comprova a marca cultural.

Figura 4 - Análise de Água Branca, 2005

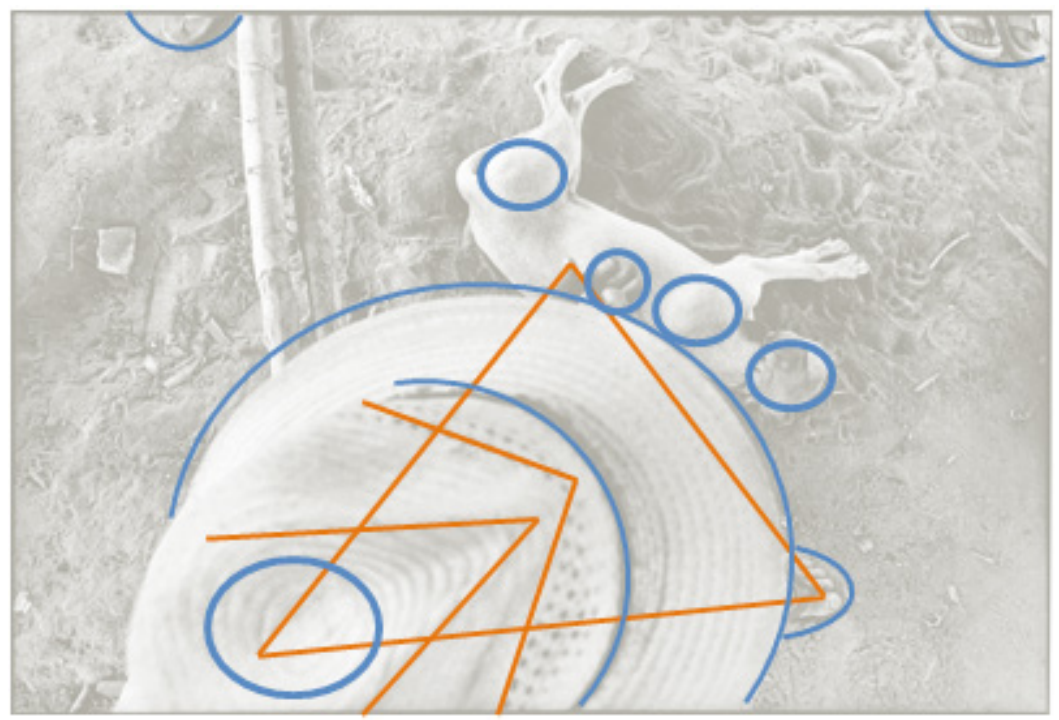

Fonte: Santana (2011)

Parece-nos evidente que a distribuição de traços retos e curvos se relaciona com base na complementaridade, dentro da criação estética deste texto visual. Porém, podemos ir adiante: se, conforme a primeira imagem analisada, associarmos os ângulos e os traços pontiagudos à marca de cultura (ou ao lado humano) no contorno da ampulheta a partir da figura do menino; nesta foto de agora tal aspecto é corroborado, porque o chapéu - um instrumento de cultura - fornece as sugestões geométricas em que predominam as estruturas triangulares. No entanto, em termos de prevalência, as circu- 
laridades parecem dominar a imagem; na mesma linha de raciocínio, supondo que as formas redondas e curvas estejam indicando a natureza ou o animal, observamos que estas imperam, na sintaxe da foto. Mesmo nas presenças humanas (na copa do chapéu, na mão do homem e nas sandálias, nos pés) isso pode ser observado, embora somente na medida em que este(s) ser(es) humano(s) está(ão) integrado(s) ao animal. 0 espaço humano "invade" o corpo do cão, assinalando a interdependência entre os seres - mas não nos esqueçamos de que há argumentos para supor que, nesta relação, o bicho ainda ocupa uma hierarquia mais prestigiosa.

De imediato, vemos que o ângulo escolhido para a captação da imagem foi novamente o plongé - o que costuma causar uma sensação de que o personagem, visto de cima para baixo, está oprimido ou apequenado ${ }^{4}$. No caso da imagem em análise, esta escolha favorece também o anonimato do indivíduo, que se esconde sob o chapéu. 0 cão, ao contrário, é visto em quase toda a sua extensão física e, apesar de submetido ao mesmo ângulo, não parece sofrer com a sensação opressiva. A sua figura foi colocada na parte superior da foto, o que lhe confere leveza. 0 homem, ao contrário, surge na parte inferior, suportando o peso visual desta posição. Ainda que levemos em conta as demais presenças humanas, sugeridas pelos pés nos cantos superiores, quase a levitar, eles não aniquilam o aspecto opressivo que parece incidir sobre o homem de chapéu.

Podemos observar que o cão, para além de estar em situação alta, leve e favorecida sob o ponto de vista da leitura do texto visual, ainda goza de um descanso sobre a textura da maciez, na terra fofa e palmilhada. Já o homem é posto na textura da aspereza e da complexidade de tramas (representada pelo

4 É o caso de lembrar, com Pietroforte (2007), que o modo de olhar instaura um modo de significação. 
chapéu). A vida dura e difícil parece pender para o lado dele, ao passo que o animal se estende na areia, em descanso. Caberia acompanhar nas fotos a categoria que o animal ilustra (doméstico, para caça, utilitário etc.), a fim de apreciar a maneira como o seu status pode mudar, na representação dada pela foto - e isso será possível em pesquisa futura, dedicada a um corpus mais extenso. Por enquanto, adiantamos que a figura do cão, diferentemente da galinha, do boi ou do peixe (que são animais para o consumo), parece se integrar de maneira bastante íntima ao cotidiano sertanejo, assim como veremos acontecer com o cavalo, o jumento. Essa afinidade ressalta a importância do animal por um componente afetivo de convivência, no espaço nordestino retratado por Tiago Santana.

\subsection{Terceira foto}

Figura 5 - Juazeiro do Norte, 1999

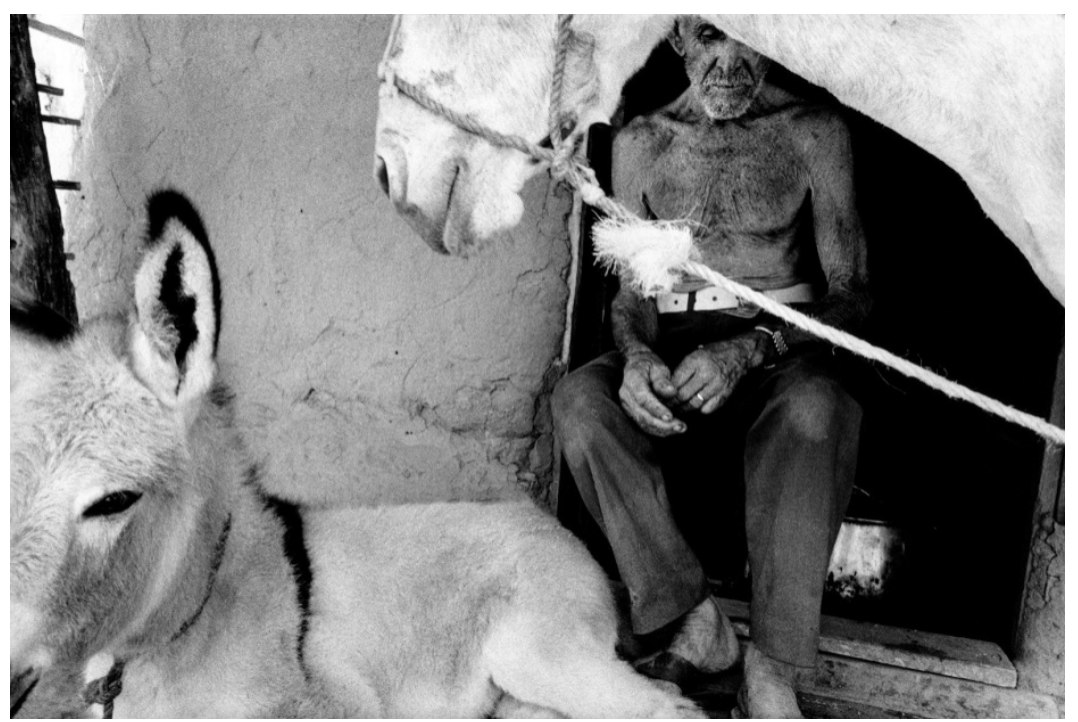

Fonte: Santana (2011) 
Nesta imagem, embora tenhamos a imagem frontal de um homem idoso, o seu rosto não parece identificável, pois a parte superior de sua cabeça surge escondida atrás de uma silhueta equina. É patente o desejo de, novamente, associar o humano ao anônimo, na medida em que os olhos do idoso tornam-se inacessíveis para nós, espectadores da imagem - mas aqui temos não somente um corte, dissociando os seres, fragmentando-os. Na verdade, temos uma simbiose criada nestas estratégicas fraturas. Uma análise detida consegue montar, como num puzzle, as peças destes corpos que, figurativamente, aparecem despedaçadas: o jumento à esquerda tem pernas, focinho, um dos olhos e uma das orelhas (do lado direito) amputados pelo enquadramento; o homem, ao centro da imagem, não apresenta os demais segmentos: olho e orelha esquerdos, topo da cabeça. 0 cavalo que surge recortado no alto da imagem, vindo da direita, é apenas um longo pescoço, focinho e lábios - o que faltou ao jumento deitado! Dessa maneira, poderíamos compreender a imagem como a sugestão de um único ser compósito entre homem e bicho, tamanha a interdependência entre estas criaturas. Entretanto, não podemos deixar de notar que, nesse recurso franksteiniano, há mais partes equinas que humanas, e isso nos leva de novo ao privilégio da natureza, relativamente à cultura, na oposição mínima que investigamos.

De maneira semelhante àquela vista na análise da primeira foto, os animais aqui se encontram num esplendor de luz e brancura, enquanto o ser humano parece mergulhar no escuro de um espaço doméstico que a pequena lamparina, inútil na soleira da porta, não se esforça por clarear. Homem e animais têm suas amarras: se o cavalo possui um cabresto, o homem surge enlaçado por um grosso cinto, pela pulseira de um relógio e pela aliança. Sua aparência meditativa, de rosto 
alongado, indica uma réplica da feição do cavalo, que se apresenta de perfil - mas indubitavelmente são suas mãos o elemento notável: elas buscam o centro da foto, como extremidades de um trapézio que é esse corpo do homem, emoldurado pelo corpo do cavalo. Se pensarmos que as mãos humanas são, de fato, símbolo de seu trabalho, do esforço e da inventividade (inclusive no ato de domesticar os animais), talvez encontremos um prestígio conferido ao homem, nesta imagem.

\subsection{Quarta foto}

Figura 6 - Icapuí, 2005

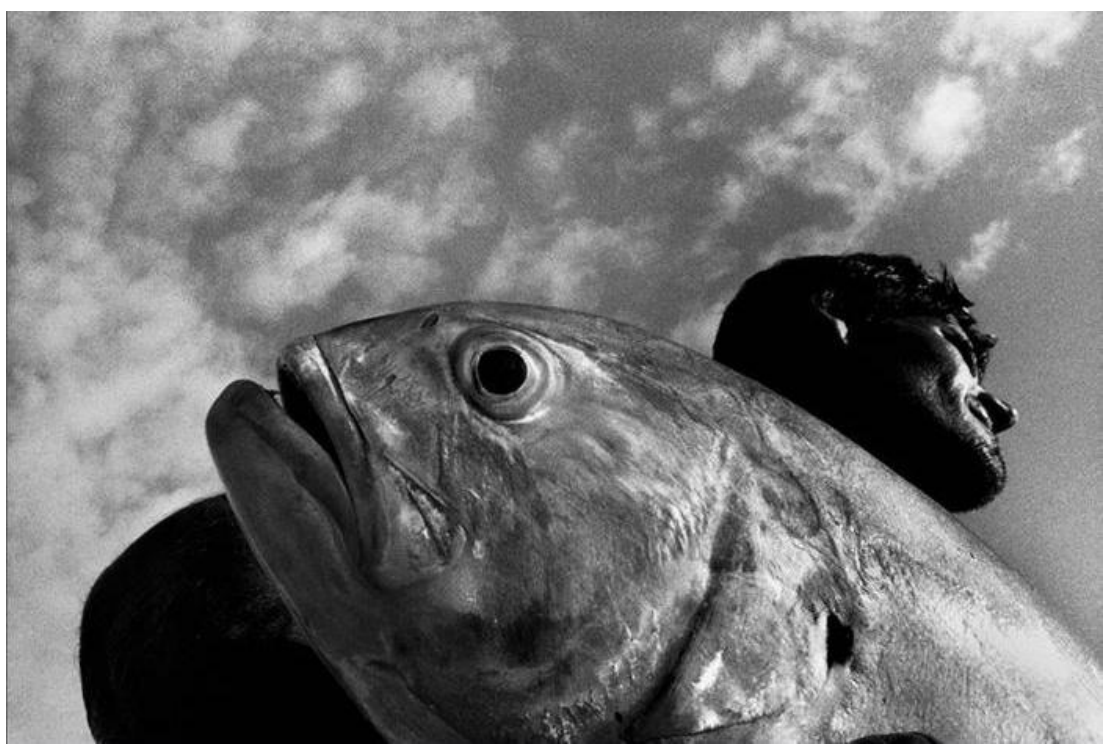

Fonte: Santana (2011)

Peixe e homem olham para direções opostas e estão representados por intensidades cromáticas decididamente 
contrárias: não à toa. Diferentemente do que vimos nas duas imagens anteriores, que mostravam animais de companhia do homem, parceiros em sua rotina e labuta, o peixe (no contexto sertanejo) significa apenas alimento. Portanto, a divergência direcional que a foto explicita pode ser resumida da seguinte maneira: o alimento para o homem representa a morte do peixe, ao passo que a vida deste último só pode ser preservada com a ausência, para o homem, de seu recurso alimentar. 0 desejo de sobreviver não pode ser respeitado nos dois casos; uma das criaturas terá de ser sacrificada - e, embora a fotografia já indique o "perdedor" nesta disputa, o peixe, vencido e morto, alcança uma importância que o homem, apesar de conquistador do alimento e da vida, não tem. É assim que vemos o animal ocupar uma área predominante da imagem, recebendo uma luz que faz ressaltar a textura de seu corpo, o prateado vívido que delineia suas expressões, dá-lhe identidade.

O homem, ao contrário, em segundo plano e coberto pelo corpo deste pescado gigantesco, apresenta um rosto indistinguível. 0 ângulo que ele ocupa, contraplongée, confirma sua superioridade na caça, assim como o brilho luminoso que vem da direita e lhe banha a cabeça - entretanto, suas feições permanecem anônimas e pouco expressivas. 0 homem, aqui, é um símbolo - mas o animal é um indivíduo. E, curiosamente, se quisermos um pouco mais de especificidade para este homem, um pouco mais de "corpo" para sua figura tão afastada da câmera, observaremos que, à semelhança do que aconteceu na fotografia que analisamos antes, uma simbiose parece acontecer. É dessa maneira que podemos enxergar o dorso do peixe funcionando como um peito postiço para o homem; e as guelras, no canto inferior, sugerem um braço que se insinua, um membro, embora flácido. Além do que, apesar de voltados para lados opostos, ambos, homem e bicho, olham para o céu, 
espaço que nenhum deles habita. Estão, portanto, irmanados pelo inalcançável, dentro dessa perspectiva - o que nos leva a constatar, outra vez, a interdependência dos elementos de nossa oposição fundamental, embora ainda com o privilégio conferido à natureza.

\subsection{Quinta foto}

Figura 7 - São Caetano, 2007

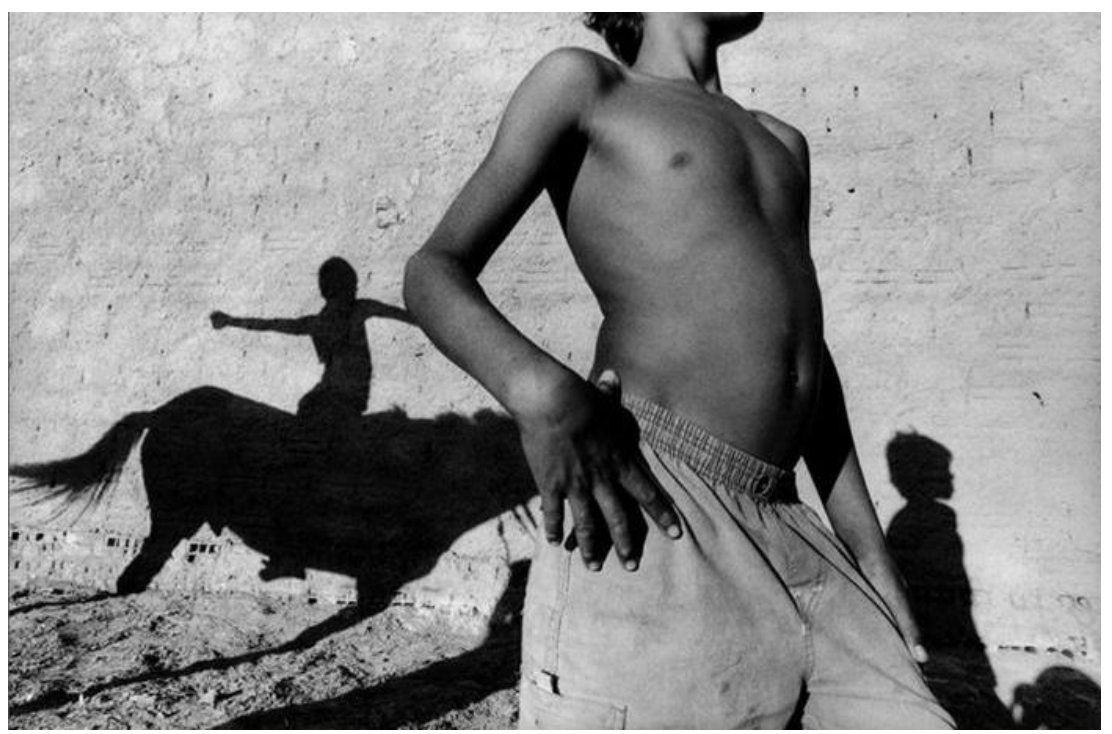

Fonte: Santana (2011)

Se pudemos, nas imagens até aqui analisadas, perceber uma integração física entre homem e animal realizada através dos recursos fotográficos, neste exemplo temos um caso magistral a confirmar nossas constatações. Através da projeção da sombra de um cavalo sobre um muro, a silhueta não somente nos mostra um interessante hibridismo entre cavaleiro 
e montaria (como se a criança que cavalga o bicho compusesse, com ele, um único ser, uma espécie de centauro ou criatura mítica), mas, para além disso, compõe, com o corpo do menino em primeiro plano, uma continuidade orgânica, na medida em que sua mão direita, aberta sobre o quadril, ocupa o lugar da cabeça do cavalo! A sugestão plástica inclusive é muito eficiente, com os dedos alongados sugerindo uma cara de perfil, e o polegar teso semelhando uma curta orelha...

Mas o mais interessante desta composição fica, novamente, por conta dos cortes fotográficos. 0 menino em primeiro plano surge decapitado pelo enquadramento, e os dois corpos infantis, projetados como sombras no muro, mantêm o anonimato justamente por serem apenas isso: sombras. A irreverência do garoto que cavalga o animal por brincadeira (não há indicação de movimento nas duas pernas projetadas, e uma outra sombra próxima, sinalizando talvez uma estaca, ou quem sabe mais um corpo humano, mostra que as rédeas estão presas) faz contraste com o menino ao centro, que parece posar, artificial e sério, enquanto sua silhueta se desenha no muro, acima da escura cabeça do fotógrafo. Esta surge à maneira de uma assinatura, no extremo canto direito da imagem.

A cena é interessante inclusive se entendermos o posicionamento das figuras num sentido cronológico, parecido ao que existia nas pinturas medievais, quando um único quadro trazia várias sequências de cenas a evoluir, em narratividade, da esquerda para a direita. Sob tal proposta, o humor lúdico evidenciado no primeiro garoto, descontraído e com os braços abertos, seria depois (numa fase subsequente da vida) substituído pela postura de seriedade do menino ao centro, que já parece encarar a responsabilidade do trabalho - e, nesse sentido, o fato de que sua mão (instrumento de tantos ofícios) esteja associada, como um prolongamento, à cabeça do 
cavalo, mostra como este animal é essencial para a labuta sertaneja. A presença do fotógrafo, que tem também sua cabeça confundida, nas sombras, com o seu instrumento de trabalho - a câmera - confirma a mensagem desta simbiose.

\section{Considerações finais}

Acreditamos que a análise aqui apresentada provou a pertinência do uso de algumas estratégias de linguagem adotadas por Tiago Santana na construção de suas imagens. 0 "parecer ser" do sertanejo, evidenciado nas fotografias, sugere a categoria formal humano/cultura vs. animal/natureza, numa tensão estabelecida conforme as propostas de Fontanille e Zilberberg (2001). Assim, tivemos dois eixos contínuos, o da intensidade e o da extensidade, a levar em conta em nossa descrição. A oposição já encontrada entre figuras humanas e animais mostra uma interdependência reveladora do mecanismo social em que o homem sertanejo vive: o seu espaço doméstico, profissional e afetivo está perpassado pela presença de bichos, a tal ponto que este muitas vezes, nas composições fotográficas, alcança uma maior evidência que o ser humano. Entretanto, a continuação de nossa pesquisa tratará de investigar a permanência ou não deste traço, numa análise expandida sobre outras vinte e cinco das principais imagens de Tiago Santana. Este futuro trabalho certamente consolidará interessantes reflexões não somente em torno da obra específica deste fotógrafo cearense, mas no campo mais amplo dos estudos semióticos sobre os textos visuais. 


\section{REFERÊNCIAS}

BERTRAND, D. Caminhos da semiótica literária. São Paulo: EDUSC, 2003.

DONDERO, M. G. "La sémiotique visuelle entre les principes généraux et specificités. A partir du Groupe $\mu$ ”. In Nouveaux Actes Sémiotiques. Actes de colloques. 2008. Disponível em: <http://revues.unilim.fr/nas/document.php?id=3286>. Acesso em: 27 jun. 2010.

DONDERO, M. G.; FOSSALI, P. B. Sémiotique de la photographie. Limoges: 2011.

FONTANILLE, J. e ZILBERBERG, C. Tensão e significação. São Paulo: Discurso Editorial, 2011.

FLOCH, J.-M. Petites mythologies de l'oeil et de l'esprit pour une sémiotique plastique. Paris/Amsterdam: Éditions Hadès Benjamin, 1985.

PIETROFORTE, A. V. Análise do texto visual - a construção da imagem. São Paulo: Contexto, 2007.

LONGHI, R. Breve mas verídica história da pintura italiana. São Paulo: Cosac Naify, 2005.

SANTANA, Tiago. Céu de Luiz. São Paulo: Tempo d'Imagem, 2014.

. Sertão. Tours: Actes Sud, 2011.

. 0 chão de Graciliano. São Paulo: Tempo d'Imagem, 2006.

Benditos. São Paulo: Tempo d'Imagem, 2000.

WÖLFFLIN, H. Conceitos fundamentais da História da Arte. Tradução de J. Azenha Jr. São Paulo: Martins Fontes, 2006. 
Tércia Montenegro LEMOS

ZILBERBERG, C. Elementos de semiótica tensiva. Tradução de I. C. Lopes, L. Tatit e W. Beividas. São Paulo: Ateliê Editorial, 2011.

Artigo recebido em abril de 2015 e aprovado em junho de 2015.

Disponível em: http://seer.fclar.unesp.br/casa 